Arq. Bras. Med. Vet. Zootec., v.68, n.2, p.506-516, 2016

\title{
Qualidade do leite e perfil das propriedades leiteiras no sul de Santa Catarina: abordagem multivariada
}

\author{
[Milk quality and profile of dairy farms in southern \\ Santa Catarina: multivariate approach] \\ D. Werncke ${ }^{1}$, A.M. Gabbi ${ }^{1}$, A.S. Abreu ${ }^{1}$, N.C. Felipus ${ }^{2}$, N.L. Machado ${ }^{2}$, L.L. Cardoso ${ }^{2}$, \\ F.A. Schmid ${ }^{2}$, D.R.M. Alessio ${ }^{2}$, V. Fischer ${ }^{3}$, A. Thaler Neto ${ }^{4}$ \\ ${ }^{1}$ Aluno de pós-graduação - Universidade Federal do Rio Grande do Sul - UFRGS - Porto Alegre, RS \\ ${ }^{2}$ Aluno de pós-graduação - Universidade do Estado de Santa Catarina - CAV/Udesc - Lages, SC \\ ${ }^{3}$ Universidade Federal do Rio Grande do Sul - UFRGS - Porto Alegre, RS \\ ${ }^{4}$ Universidade do Estado de Santa Catarina - CAV/Udesc - Lages, SC
}

\begin{abstract}
RESUMO
O objetivo do presente estudo foi caracterizar as propriedades leiteiras da região do Vale do Braço do Norte, sul de Santa Catarina, Brasil, quanto à qualidade do leite e ao perfil em infraestrutura, manejo e alimentação dos animais. Foram coletadas informações de 50 propriedades leiteiras, obtidas por meio da aplicação de um questionário estruturado, abrangendo questões socioeconômicas dos produtores, manejo do rebanho, estrutura da propriedade, caracterização dos animais, alimentação das vacas além de manejo e higiene da ordenha. As amostras de leite foram submetidas a análises de composição, contagem bacteriana total, contagem de células somáticas e estabilidade do leite ao teste do álcool. Os dados foram analisados pela análise fatorial, discriminante, canônica, e de agrupamento. As propriedades têm como principal característica a agricultura familiar, com área média de 30 hectares; destes, 15,1 são destinados à pecuária leiteira, com média de 23,1 vacas ordenhadas. $\mathrm{Na}$ análise fatorial, o primeiro fator representa as relações entre as práticas de higiene na ordenha e de controle/prevenção de mastite, o segundo fator compreende a infraestrutura da fazenda com o nível de produção e o terceiro fator demonstra a relação entre a suplementação concentrada, a produção e a estabilidade do leite ao teste do álcool. A análise de agrupamento formou três grupos, sendo dois compostos por produtores com maior nível tecnológico e outro constituído por pequenos produtores com menor infraestrutura e nível de tecnologia. As propriedades que apresentam infraestrutura mais adequada para a produção, maior adoção das práticas recomendadas de manejo de ordenha e critérios de alimentação mais adequados produzem leite com melhor qualidade.
\end{abstract}

Palavras-chaves: contagem de células somáticas, contagem bacteriana total, composição do leite, estabilidade do leite ao álcool, manejo de ordenha

\begin{abstract}
The aim of this study was to characterize the dairy farms of the Vale do Braço do Norte region, south of Santa Catarina State, Brazil, regarding milk quality and profile of the farms for infrastructure, management and nutrition of the animals. Information about 50 dairy farms was obtained through a survey regarding socio-economic conditions of the farmers, farm structure, characterization of animals, cow feeding and also milking management and hygiene. The milk samples were analyzed for total bacterial count, somatic cell count and stability of milk to ethanol. The data were analyzed in factorial, discriminant, canonical and cluster analysis. The main characteristic of farms is family farming with an average area of 30 hectares, of which 15.1 are destined for dairy farming, where an average of 23.1 cows are milked. On the factor analysis, the first factor represents the relation between hygiene practices during milking and control / prevention of mastitis, the second factor comprises the infrastructure of the
\end{abstract}

Recebido em 24 de abril de 2015

Aceito em 22 de setembro de 2015

E-mail: manawerncke@gmail.com 
farm with the level of production and the third factor shows the ratio of concentrate supplementation, production and stability of the milk to the ethanol test. The cluster analysis formed three groups, two composed of producers with higher technological level and another by small producers with lower infrastructure and level of technology. The dairy farms that have more adequate infrastructure for production, greater adoption of practices recommended for milking management and more appropriate criteria for cow feeding produce better quality milk.

Keywords: ethanol stability of milk, milking management, milk composition, somatic cell count, total bacterial count

\section{INTRODUÇÃO}

A pecuária leiteira é praticada em todo o Brasil, com produtores em vários níveis organizacionais e tecnológicos, que vão desde a agricultura familiar, pequenas cooperativas até propriedades com elevado nível tecnológico (Willers et al., 2014). Essa atividade é de suma importância para o país, tanto no contexto social quanto no econômico.

Para que o Brasil possa se tornar mais competitivo no mercado internacional, é necessário, entre outros aspectos, que os produtores e técnicos ligados à cadeia produtiva busquem melhorar o processo de obtenção do leite, melhorando a qualidade do produto e a segurança alimentar do consumidor, cada vez mais exigente, que demanda alimentos mais saudáveis. Dessa forma, o produtor necessita alterar a forma de obtenção, que vem sendo praticada há décadas, a fim de adequar-se à legislação e às exigências do mercado consumidor, mantendo a atividade rentável (Picolli et al., 2014). A maioria dos produtores ainda realiza práticas de higiene de ordenha e de gestão agrícolas ineficazes, resultando em leite de baixa qualidade, com grandes perdas econômicas para a indústria (Yuen et al., 2012).

Para que essa adequação possa ser feita da melhor forma possível, torna-se necessário conhecer as características dos sistemas de produção. A identificação das características de produção, das técnicas de manejo, entre outras informações, pode auxiliar no direcionamento da assistência técnica, visando ao aconselhamento específico para a melhoria da produção e da qualidade do leite produzido (Bodenmüller-Filho et al., 2010). Dessa forma, o objetivo do presente estudo foi caracterizar as propriedades leiteiras da região do Vale do Braço do Norte, sul de Santa Catarina, Brasil, quanto à qualidade do leite e ao perfil das propriedades, em infraestrutura, manejo e alimentação dos animais.

\section{MATERIAL E MÉTODOS}

$\mathrm{O}$ estudo foi realizado em oito municípios localizados no Vale do Braço do Norte, localizado na região sul do estado de Santa Catarina (SC), com clima Cfa (clima subtropical úmido), segundo a classificação de Köppen, com pluviosidade anual média de 1497,6mm (Silva et al., 2002).

O estudo foi realizado em uma amostra de 50 propriedades leiteiras, representativas da região, perfazendo aproximadamente $20 \%$ das propriedades leiteiras fornecedoras de leite para duas indústrias de laticínios localizadas na região, as quais adquirem o leite e prestam assistência técnica aos produtores. Como critério de representatividade da região, foi priorizado o volume diário de leite comercializado. Para a seleção dos produtores, estes foram ordenados por volume de leite comercializado no mês do início do experimento. A partir da base de dados ordenada, excluíam-se quatro produtores, selecionando o produtor seguinte. Esta etapa foi repetida do maior ao menor produtor, objetivando obter uma amostra proporcional em relação ao volume de leite comercializado.

As informações referentes às propriedades leiteiras foram obtidas mediante a aplicação de um questionário estruturado, abrangendo questões socioeconômicas dos produtores, rebanho, estrutura da propriedade, caracterização e alimentação dos animais e emprego de técnicas de manejo relacionadas à qualidade do leite. $\mathrm{O}$ projeto de pesquisa foi aprovado pelo Comitê de Ética em Seres Humanos da Universidade do Estado de Santa Catarina (Udesc), número de referência 65/2011. 
Nos três meses seguintes à aplicação do questionário, foram coletadas amostras mensais de leite de cada propriedade para serem realizadas as análises do teste do álcool, contagem bacteriana total (CBT), contagem de células somáticas (CCS) e composição química e estabilidade ao teste do álcool. Duas amostras mensais de cada propriedade foram encaminhadas para o Laboratório da Associação Paranaense de Criadores de Bovinos da Raça Holandesa (APCBRH), sendo a primeira para determinação da contagem bacteriana total (CBT) e a segunda para contagem de células somáticas (CCS) e composição química do leite. A CBT e a CCS foram determinadas por meio da técnica de citometria de fluxo, e a composição química (teores de sólidos totais, a gordura, a lactose e a proteína bruta) pelo método de espectrometria por radiação infravermelha. Uma terceira amostra foi utilizada para a determinação da estabilidade ao teste do álcool. O teste do álcool foi realizado mensalmente mediante a mistura de $2 \mathrm{~mL}$ de leite e $2 \mathrm{~mL}$ da solução alcoólica, em uma placa de Petri, sendo esta amostra agitada por alguns segundos (Tronco, 2010). Foi considerada a menor concentração alcoólica em que se visualizava precipitação. Foram utilizadas as concentrações alcoólicas de $68,70,72,74,76,78,80$ e $82 \%$ de etanol v/v.

Os dados foram avaliados por meio de técnicas de análise multivariada (análise fatorial e de agrupamento), utilizando-se o programa estatístico SAS ${ }^{\circledR}$ (SAS Institute, 2002). Foram avaliados dados referentes à qualidade microbiológica, composição e análise físicoquímica do leite, manejo de ordenha, infraestrutura da propriedade, quantidade de leite produzido e aporte nutricional do rebanho. Para as variáveis relacionadas à qualidade do leite, foi utilizada a média geométrica das três amostras analisadas, sendo os dados da CBT e CCS submetidos à transformação logarítmica $\left(\log _{10}\right)$. As variáveis utilizadas foram previamente padronizadas pelo procedimento STANDARD e selecionadas pela sua comunalidade para compor os fatores. A análise fatorial foi realizada utilizando-se o procedimento FACTOR e considerando-se a variância comum entre as variáveis, com rotação Promax, que, por ser uma rotação oblíqua, considera a relação entre os fatores, quando esta existe. Para a análise de agrupamento, utilizaram-se os procedimentos FASTCLU e CLUSTER, sendo usado o procedimento DISCRIM, seguido do STEPDISC e do CANDISC, como análise confirmatória, empregando-se o método de Ward, baseado na distância euclidiana. A comparação entre os grupos formados foi realizada por análise multivariada de variância (MANOVA), utilizando-se o procedimento GLM, sendo as médias dos grupos comparadas pelo teste TukeyKramer, ao nível de significância de 5\%.

\section{RESULTADOS E DISCUSSÃO}

A região caracteriza-se por apresentar propriedades leiteiras com áreas restritas, sendo a área média e o desvio-padrão de $30 \pm 20$ hectares (ha), variando de 3,7 a 90ha, com mão de obra familiar e ênfase na atividade leiteira. Desta área, em média, $15,1 \pm 8,3$ ha são utilizados para a produção de leite, sendo aproximadamente 10ha para pastagem e 3ha para confecção de silagem de milho e/ou sorgo. Esta técnica de conservação de forragem é adotada por $92 \%$ dos produtores, com área plantada de 1 a 8 ha. Características semelhantes foram identificadas em outras regiões do sul do Brasil. Nas regiões do Alto Vale do Itajaí e Oeste catarinense, as propriedades possuíam uma área média de $30 \pm 29$ ha, sendo $70 \%$ das propriedades com menos de 30ha (Winck e Thaler Neto, 2012).

Os produtores possuem, em média, $29 \pm 18$ vacas leiteiras (variando de seis a 103), das quais

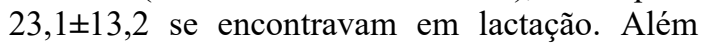
disso, de acordo com as informações dos produtores, eles possuíam $22 \pm 16$ bezerras e novilhas, perfazendo $51 \pm 33$ bovinos de leite. $\mathrm{Na}$ maioria das propriedades predomina a raça Jersey, raça esta presente em quase todas. A produção média diária de leite informada pelos produtores foi de 258,2 $\pm 237,6$ litros (variando de 40 a 1200 litros). Outro trabalho realizado em Santa Catarina demonstrou o predomínio da raça Jersey na região do Alto Vale do Itajaí em 58,2\% das propriedades, enquanto na região do MeioOeste, em 58,3\% das propriedades predominava a raça Holandesa (Winck e Thaler Neto, 2012).

O sistema de produção predominante é baseado em pastagem com suplementação com concentrado e forragem conservada (silagem). No verão, a principal estratégia alimentar é o pastejo rotacionado, com trocas diárias de piquetes, predominantemente em pastagens perenes formadas por diversas espécies de 
gramíneas (Axonopus compressus, Brachiaria decumbens, Eriochola polystach) e, em alguns casos, leguminosas (Trifolium repens L; Arachis pintoi). Esse tipo de manejo ocorre devido aos programas de extensão desenvolvidos para capacitação dos produtores rurais, com técnicas e estratégias relacionadas ao manejo de pastagens. Nessa estação, é baixa a utilização de forragem conservada, e $21,5 \%$ de produtores utilizam capineiras como capim-elefante (Pennisetum purpureum), cana-de-açúcar (Saccharum officinarum L.) ou planta de milho (Zea mays), fornecidos picados aos animais. A utilização de alimentos obtidos das próprias fazendas tem um impacto positivo na redução dos custos de produção na atividade (Yalçin et al., 2010).

No outono/inverno/primavera, predominam as pastagens anuais temperadas, em especial aveia (Avena sativa) e azevém (Lolium multiflorum), com suplementação de silagem de milho ou sorgo, alimento disponível em $92 \%$ das propriedades nessas épocas. Alguma suplementação com concentrado é utilizada durante todo o ano, sendo usados concentrados comerciais, além de milho, casca de soja, soja grão, farelo de arroz, farelo de trigo e resíduo úmido de cervejaria.

A mão de obra é essencialmente familiar, e todos os produtores são alfabetizados, entretanto a maioria apresenta baixo nível de escolaridade, sendo 58\% com nível fundamental incompleto. Aproximadamente $68 \%$ dos produtores estão na atividade há mais de 10 anos e a maioria (68\%) pretende aumentar sua produção de leite no futuro. Apenas $26 \%$ dos produtores vivem exclusivamente do leite, no entanto 4471 e $28 \%$ dos produtores afirmam que o leite é, respectivamente, sua primeira ou segunda atividade. O baixo nível de escolaridade dos produtores rurais, o elevado tempo de permanência na atividade leiteira e o desenvolvimento de diferentes atividades dentro de uma mesma propriedade também foram observados nas regiões do Oeste, Noroeste, Meio-Oeste, Alto Vale do Itajaí no estado de Santa Catarina e na região serrana e sul do estado do Rio Grande do Sul (Machado, 2010; Winkler, 2010; Winck e Thaler Neto, 2012; Costa et al., 2013).

As vacas são ordenhadas em estábulos de madeira ou concreto, com piso de concreto
$(43 \%)$ e salas de ordenha com fosso (43\%); os demais, entretanto, ainda utilizam estábulos de chão batido. A ordenha mecânica com balde ao pé é realizada em $47 \%$ das propriedades, e a ordenha canalizada ou com transferidor de leite em 51\%; apenas um produtor realizava ordenha manual. O armazenamento e o resfriamento do leite são realizados em tanques de expansão $(82 \%)$ ou em tanques de imersão $(18 \%$ das propriedades). Uma realidade semelhante foi encontrada na região noroeste de Santa Catarina por Costa et al. (2013), onde 64\% das propriedades realizavam a ordenha com balde ao pé e apenas $36 \%$ das propriedades possuíam sala de ordenha com fosso. Entretanto, Winck e Thaler Neto (2012), nas regiões do Alto Vale do Itajaí e Meio-Oeste de Santa Catarina, verificaram que $33,7 \%$ das propriedades realizavam ordenha manual, o estábulo convencional estava presente em 94\% das propriedades e apenas $6 \%$ das propriedades possuíam sala de ordenha com fosso. Esses autores observaram ainda que $96,4 \%$ das propriedades possuíam o sistema de ordenha do tipo balde ao pé, apenas 3,6\% possuíam ordenha canalizada, e, com relação ao sistema de resfriamento do leite, 56,6\% das propriedades apresentavam tanque de imersão, sendo apenas 24,2\% com tanque de expansão. Apenas parte dos produtores utilizava técnicas de manejo recomendadas para a ordenha, como pré-dipping (25\%), pós-dipping (49\%), ordenha em separado dos primeiros jatos de leite $(60 \%)$, Califórnia Mastitis Test (CMT) (51\%), e tratamento intramamário no período seco $(37 \%$ das propriedades). Quase um terço dos produtores ainda não adota procedimentos adequados de higiene dos equipamentos de ordenha, com detergentes específicos.

Destaca-se que $96 \%$ das propriedades participantes deste estudo não realizavam nenhum tratamento na água utilizada no processo de ordenha e higienização dos equipamentos. A baixa utilização das práticas de higiene na ordenha e de tratamento da água usada no processo de ordenha e higienização dos equipamentos afeta negativamente a eficiência e melhoria da produção e da qualidade do leite produzido na região. Segundo Elmoslemany et al. (2010), as propriedades que não realizam nenhum tipo de tratamento de água tem 5,5 vezes mais chances de apresentar elevada contaminação bacteriana no leite do que fazendas 
que realizam algum tipo de tratamento de água. O tratamento da água utilizada no processo de ordenha é importante, pois ele reduz a carga microbiana presente na água (Rangel et al., 2014). A Instrução Normativa 62 (BRASIL, 2011) exige que a água usada no processo de ordenha seja tratada, uma vez que, para se obter leite de qualidade, é necessário utilizar água com qualidade microbiológica adequada para a limpeza e sanificação de equipamentos e utensílios de ordenha.

$\mathrm{Na}$ análise fatorial, os três primeiros fatores explicam $60,8 \%$ da variação total; em razão das variáveis que o primeiro fator representa, este pode ser denominado manejo de higiene de equipamentos e práticas de ordenha; o segundo fator representa a infraestrutura da fazenda e a quantidade de leite produzido, enquanto o terceiro fator está mais relacionado ao aporte nutricional do rebanho e sua relação com a produção por vaca e estabilidade do leite. Os três fatores (Tab. 1) que caracterizam as propriedades leiteiras na região sul do estado de Santa Catarina foram semelhantes aos de outros estudos realizados na região sul do estado do Rio Grande do Sul/Brasil (Gabbi et al., 2013) e ao estudo realizado por Garcia et al. (2012) na região central do México.

Tabela 1. Cargas fatoriais, comunalidades e percentual de variância da caracterização das propriedades leiteiras na região sul de Santa Catarina, Brasil

\begin{tabular}{|c|c|c|c|c|c|}
\hline \multirow{2}{*}{ Atributos } & \multirow{2}{*}{$\begin{array}{c}\text { Média } \pm \\
\text { desvio-padrão }\end{array}$} & \multicolumn{3}{|c|}{ Fatores } & \multirow{2}{*}{ Comunalidades } \\
\hline & & 1 & 2 & 3 & \\
\hline Área destinada à prod. leite (ha) & $15,1 \pm 8,3$ & 0,0078 & 0,6310 & $-0,0485$ & 38,7 \\
\hline Número de vacas em lactação & $23,1 \pm 13,2$ & 0,0542 & 0,8837 & $-0,0439$ & 80,0 \\
\hline Produção de leite (kg/dia) & $258,2 \pm 237,6$ & 0,0789 & 0,7665 & 0,2057 & 78,5 \\
\hline Produção de leite/vaca/dia & $10,44 \pm 4,96$ & 0,0571 & 0,2476 & 0,5958 & 54,3 \\
\hline Tipo de ordenha ${ }^{1}$ & $50,0 \% *$ & 0,3095 & 0,5778 & 0,1784 & 71,2 \\
\hline Estrutura do local ordenha ${ }^{2}$ & $44,0 \% *$ & 0,5355 & 0,4669 & 0,0552 & 74,8 \\
\hline Pré-dipping ${ }^{3}$ & $26,0 \% *$ & 0,6721 & 0,1552 & $-0,0985$ & 49,6 \\
\hline Pós-dipping 4 & $50,0 \% *$ & 0,8844 & 0,0977 & $-0,3354$ & 67,0 \\
\hline Terapia da vaca seca ${ }^{5}$ & $38,0 \% *$ & 0,7717 & $-0,1438$ & 0,1997 & 70,0 \\
\hline Higiene de equipamentos ${ }^{6}$ & $60,0 \% *$ & 0,7268 & 0,0704 & 0,0724 & 63,2 \\
\hline $\begin{array}{l}\text { Suplementa com concentrado } \\
\text { conforme produção }\end{array}$ & $58,0 \% *$ & $-0,0795$ & $-0,0578$ & 0,7736 & 52,9 \\
\hline Tipo de concentrado ${ }^{8}$ & $36,7 \% *$ & 0,1291 & 0,0139 & 0,6782 & 56,7 \\
\hline CBT $\left(\log _{10}\right) / \mathrm{mL}$ & $5,4 \pm 0,7$ & $-0,8377$ & 0,0973 & $-0,0506$ & 67,8 \\
\hline $\operatorname{CCS}\left(\log _{10}\right) / \mathrm{mL}$ & $5,7 \pm 0,3$ & $-0,5224$ & 0,6663 & $-0,1884$ & 50,3 \\
\hline $\begin{array}{l}\text { Concentração de álcool em que } \\
\text { o leite precipita }(\%)\end{array}$ & $75,5 \pm 3,2$ & $-0,1591$ & $-0,0114$ & 0,6647 & 36,3 \\
\hline
\end{tabular}

\footnotetext{
\begin{tabular}{lccc}
\hline$\%$ Variância total & 39,4 & 12,5 & 8,9 \\
\hline${ }^{1}$ Balde ao pé 1, ordenha semi ou canalizada $2 ;{ }^{2}$ estábulo convencional & 1, sala de ordenha $2 ;{ }^{3}$ não usa pré-dipping 1,
\end{tabular} usa pré-dipping $2 ;{ }^{4}$ não usa pós-dipping 1 , usa pós-dipping $2 ;{ }^{5}$ não faz terapia intramamária da vaca seca 1 , faz às vezes 2 faz terapia da vaca seca 3; ${ }^{6}$ não utiliza água quente, detergente ácido e alcalino 1 , utiliza água quente, detergente ácido e alcalino 2; 7 não fornece concentrado conforme a produção de leite 1, fornece concentrado conforme a produção de leite $2 ;{ }^{8}$ fornece concentrado energético 1 , fornece concentrado proteico 2 , fornece concentrado energético e proteico 3.

*Percentual de produtores no nível mais elevado.
}

O primeiro fator (Tab. 1 e Fig. 1) apresenta uma relação altamente positiva entre a utilização de pré-dipping, pós-dipping, técnica adequada de higienização de equipamentos de ordenha e terapia da vaca seca. Observou-se uma relação inversa entre as variáveis anteriormente citadas com a contagem bacteriana total (CBT) e com a contagem de células somáticas (CCS). A relação altamente positiva entre as práticas de higiene na ordenha (F1+ na Fig. 1) indica que a adoção de práticas de higiene na ordenha e de controle/prevenção de mastite não se dá de forma isolada. Dessa forma, os produtores que possuem sala de ordenha com fosso utilizam, por 
exemplo, pré-dipping, apresentam maior probabilidade de realizar a terapia da vaca seca, realizar uma adequada higiene de ordenha e de equipamentos, com a utilização de detergente alcalino, ácido e água quente. Picolli et al. (2014) observaram que o tipo de local de ordenha, a adoção de técnicas recomendadas no manejo de ordenha e as instalações da sala de ordenha são fatores que influenciam a ocorrência de agentes infecciosos no leite, ou seja, a utilização de técnicas de manejo ineficientes e de instalações precárias dificulta o processo de higiene e limpeza, aumentando as contagens de microrganismos no leite e os riscos de ocorrência de mastite.

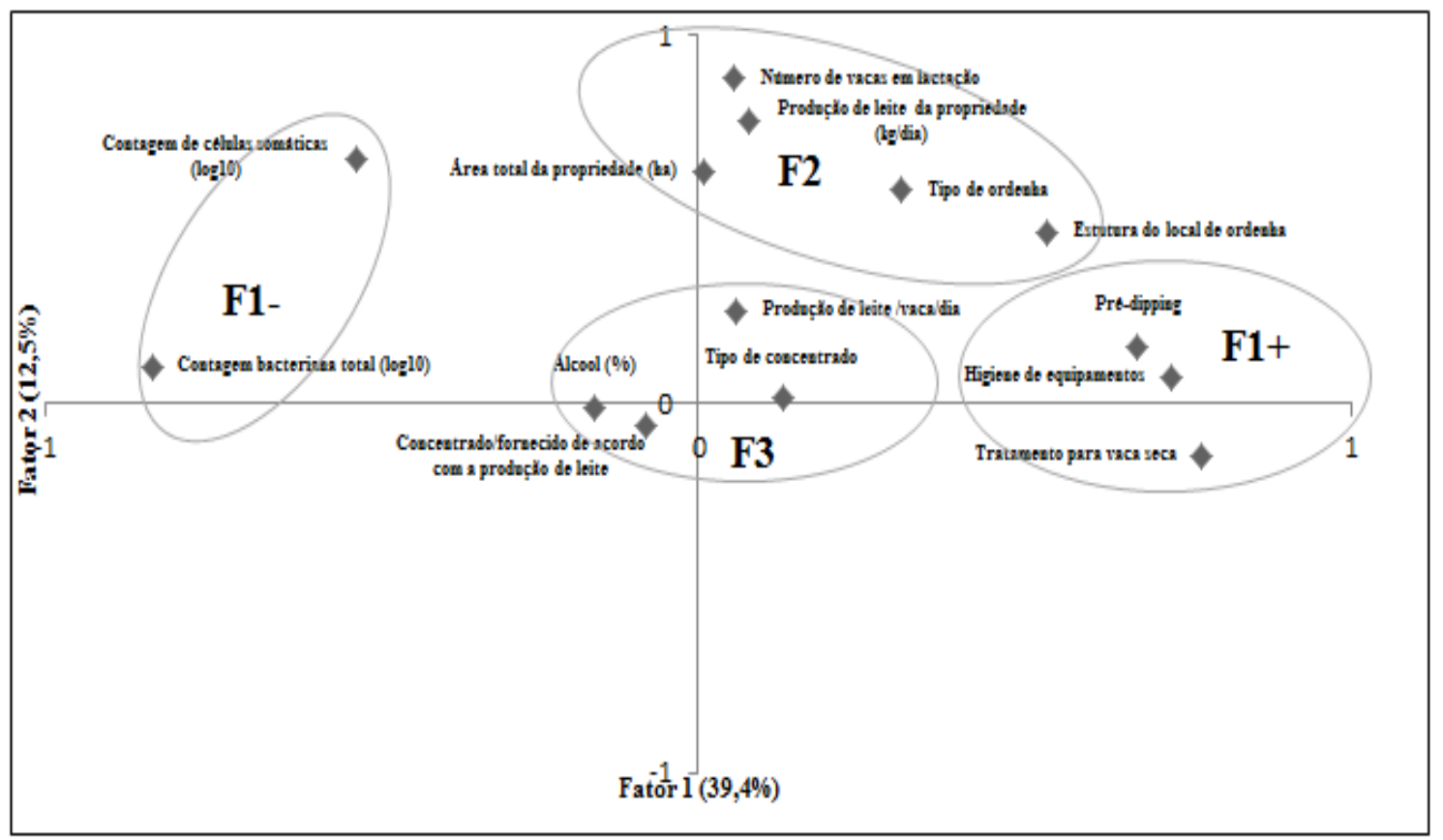

Figura 1. Dispersão das cargas fatoriais, na caracterização das propriedades leiteiras na região sul de Santa Catarina, Brasil, e identificação das variáveis relacionadas aos fatores 1 (F1+ e F1-), 2 (F2) e 3 (F3).

As cargas fatoriais (Tab. 1 e Fig. 1) negativas da CCS e da CBT (F1-), em oposição às positivas das variáveis relacionadas ao pré e pós-dipping, à terapia da vaca seca, à higiene dos equipamentos $(\mathrm{F} 1+)$, são decorrentes dos efeitos benéficos dessas práticas, diminuindo a contaminação bacteriana e reduzindo a mastite no rebanho. Os resultados do presente estudo coincidem com os encontrados por Moreira et al. (2014) e Miguel et al. (2012). A adoção de técnicas de manejo de ordenha pode reduzir em $55,65 \%$ a contagem de células somáticas e em 93,95\% a contagem bacteriana total (Valling et al., 2009).

O segundo fator apresentou uma relação positiva entre número de vacas em lactação, produção de leite, tipo de ordenha, estrutura do local de ordenha e área total da propriedade (F2 na Fig.1), demonstrando a relação entre infraestrutura da fazenda e produção de leite e impactando favoravelmente sobre o volume entregue pela fazenda, mas com uma menor associação com a produção de leite da vaca. Assim, o maior retorno financeiro, obtido por meio da comercialização do maior volume de leite, favorece a disponibilidade de maiores investimentos para melhoria da estrutura da propriedade.

A relação positiva entre o aporte nutricional, representado pela quantidade e pelo tipo de concentrado fornecido, a produção de leite/vaca/dia e a estabilidade do leite (Tab. 1 e Fig. 2) ressalta a importância do aporte energético para sustentar a produção e a síntese dos componentes lácteos, com reflexos positivos sobre a estabilidade do leite. 


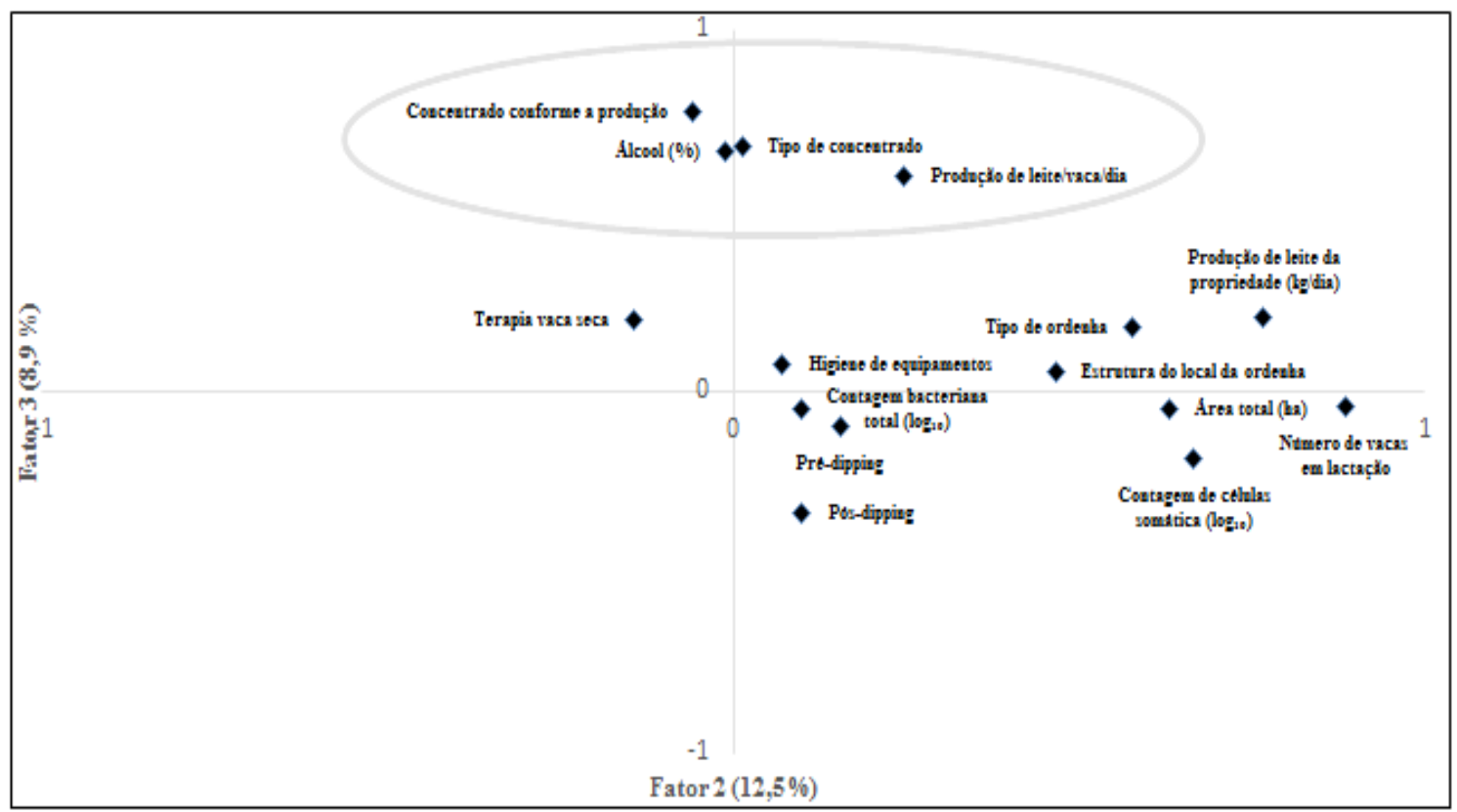

Figura 2. Dispersão das cargas fatoriais do segundo e do terceiro fator, na caracterização das propriedades leiteiras na região sul de Santa Catarina, Brasil, e identificação das variáveis relacionadas aos fatores 2 e 3 .

Ao serem atendidas as necessidades nutricionais dos animais, obtém-se como resposta maior produção de leite/vaca/dia, tendo como suporte a maior disponibilidade de nutrientes destinados para a produção de leite. A mesma situação ocorre com a estabilidade do leite, ou seja, quanto maior o aporte nutricional, principalmente energético, disponibilizado de forma balanceada para produção de leite, maior será a estabilidade do leite ao teste do álcool. Em um estudo realizado no Chile, Barchiesi-Ferrari et al. (2007) observaram que a produção de leite com baixa estabilidade era proveniente de propriedades que utilizavam alimentos de baixa qualidade. Outros estudos também observaram uma relação positiva entre a qualidade nutricional dos alimentos com a estabilidade do leite ao teste do álcool (Zanela et al., 2006; Marques et al., 2010; Stumpf et al., 2013; Gabbi et al., 2013). As elevadas comunalidades para todas as variáveis incluídas na análise demonstram a importância destas para caracterizar as propriedades leiteiras na região.

A análise canônica (Fig. 3) conseguiu capturar a diferença entre os grupos formados pela análise de agrupamento e tem a finalidade de demonstrar graficamente as distâncias utilizadas na separação dos grupos. O grupo 1 difere do 2 nas variáveis tipo de ordenha, estrutura do local de ordenha, pós-dipping, higiene dos equipamentos, utilização de capineiras, concentrado conforme a produção, produção de leite $(\mathrm{kg} /$ dia) e produção de leite/vaca/dia, raça e CBT. Os grupos 1 e 2 diferenciam-se do grupo 3 em funcão das variáveis estrutura do local da ordenha, prédipping, terapia da vaca seca, tipo de concentrado utilizado, higiene dos equipamentos, produção de leite/vaca/dia, composição do leite, instabilidade do leite ao teste do álcool, CBT e raça.

$\mathrm{Na}$ análise discriminante (Tab. 2), por meio do procedimento STEPDISC, foram incluídas no modelo final $(\mathrm{P}<0,05)$ somente as variáveis importantes para a diferenciação dos grupos de propriedades leiteiras, ou seja: a estrutura do local de ordenha seguida da produção de leite/vaca/dia, da higiene de equipamentos, do tipo de ordenha, do pré-dipping, do teor de proteína do leite, da raça, da terapia da vaca seca e do uso de capineiras. 


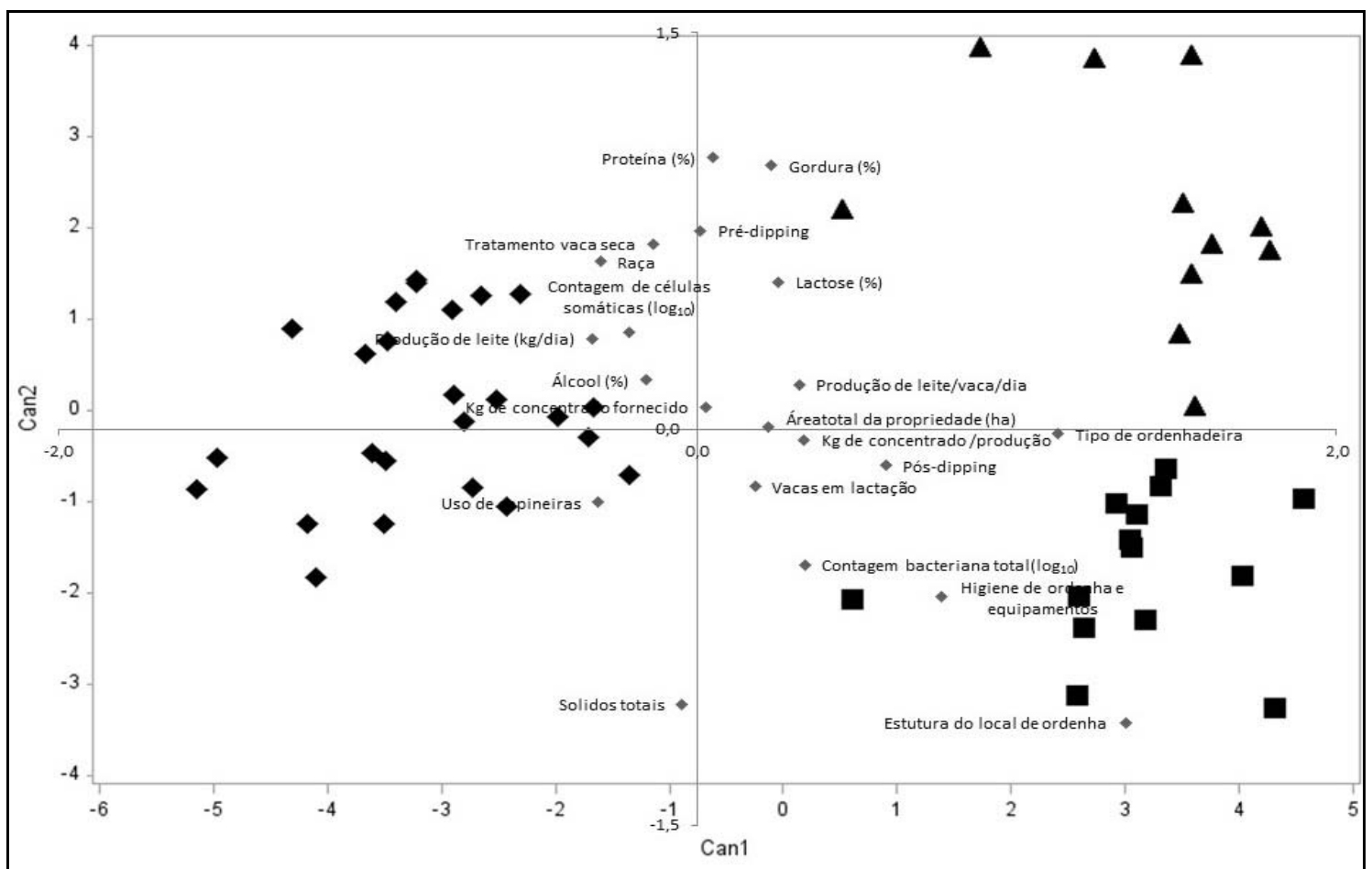

Figura 3. Análise canônica com as características das propriedades leiteiras na região sul do estado de Santa Catarina, Brasil. Grupo $1(\bullet)$; grupo $2(\boldsymbol{A})$; grupo 3(ם).

Tabela 2. Valores dos atributos com base na análise discriminante das características das propriedades leiteiras na região sul de Santa Catarina, Brasil

\begin{tabular}{lcccc}
\multicolumn{1}{c}{ Atributos } & $\mathrm{R}^{2}$ parcial & $\mathrm{P}>\mathrm{F}$ & $\mathrm{P}<$ Lambda & $\mathrm{P}>$ ASCC $^{*}$ \\
\hline Estrutura do local ordenha $^{1}$ & 0,7918 & $<0,0001$ & $<0,0001$ & $<0,0001$ \\
Produção de leite/vaca/dia $^{\text {Higiene de equipamentos }}{ }^{2}$ & 0,2360 & 0,0020 & $<0,0001$ & $<0,0001$ \\
Hipo de ordenha $^{3}$ & 0,1977 & 0,0070 & $<0,0001$ & $<0,0001$ \\
Pré-dipping $^{4}$ & 0,1936 & 0,0088 & $<0,0001$ & $<0,0001$ \\
Teor de proteína $^{\text {Raça }}{ }^{5}$ & 0,1791 & 0,0144 & $<0,0001$ & $<0,0001$ \\
Terapia da vaca seca $^{6}$ & 0,2326 & 0,0039 & $<0,0001$ & $<0,0001$ \\
Capineiras $^{7}$ & 0,1323 & 0,0545 & $<0,0001$ & $<0,0001$ \\
\hline
\end{tabular}

*ASCC: Average Squared Canonical Correlation.

${ }^{1}$ Estábulo convencional 1 , sala de ordenha $2 ;{ }^{2}$ não utiliza água quente, detergente ácido e alcalino 1 , utiliza água quente, detergente ácido e alcalino $2 ;{ }^{3}$ balde ao pé 1 , ordenha semi ou canalizada $2 ;{ }^{4}$ não usa pós-dipping 1 , usa pósdipping $2 ;^{5}$ diversas raças 1 , somente Jersey $2 ;{ }^{6}$ não faz terapia intramamária da vaca seca 1 , faz às vezes 2 , faz terapia da vaca seca $3 ;{ }^{7}$ não utiliza capineiras 1 , utiliza capineiras 2.

A análise de agrupamento formou três grupos (Tab. 3). Os grupos 1 e 2 são compostos por produtores com maior nível tecnológico, onde se tem propriedades mais bem estruturadas para a ordenha, maior adoção das práticas de manejo de ordenha e com maior critério na alimentação dos animais. Os grupos 1 e 2 diferem na produção de leite, produção de leite/vaca/dia, raça, uso de prédipping, teor de proteína, lactose e sólidos totais do leite, com uma superioridade do grupo $2 \mathrm{em}$ relação ao grupo 1, provavelmente pelo fato de o grupo 2 apresentar predomínio de animais da raça Jersey (1,91), enquanto o grupo 1 é composto por diversos grupamentos genéticos. 
Considerando-se que os rebanhos Jersey da região são constituídos de animais especializados, compreende-se a maior produção de leite e o maior teor de sólidos apresentados no grupo 2. Segundo Eckstein et al. (2014), o teor de sólidos totais tem sido cada vez mais valorizado pelas indústrias de laticínios, visto que tem relação direta com o rendimento industrial.

Tabela 3. Agrupamentos dos atributos técnicos para os grupos de propriedades leiteiras na região sul do estado de Santa Catarina, Brasil

\begin{tabular}{|c|c|c|c|c|}
\hline Atributo & $\begin{array}{c}\text { Grupo1 } \\
(n=14)\end{array}$ & $\begin{array}{c}\text { Grupo2 } \\
(n=11)\end{array}$ & $\begin{array}{c}\text { Grupo } 3 \\
(n=25)\end{array}$ & $\mathrm{P}>\mathrm{F}$ \\
\hline Área total (ha) & $20,18 \mathrm{a}$ & $16,50 \mathrm{ab}$ & $11,70 \mathrm{~b}$ & $=0,0050$ \\
\hline Número de vacas em lactação & $29,76 \mathrm{a}$ & $34,08 \mathrm{a}$ & $14,97 \mathrm{~b}$ & $=0,0005$ \\
\hline Produção de leite (kg/dia) & $296,07 b$ & $512,72 \mathrm{a}$ & $133,28 \mathrm{c}$ & $<0,0001$ \\
\hline Produção de leite/vaca/dia & $10,24 \mathrm{~b}$ & $15,65 \mathrm{a}$ & $8,26 \mathrm{~b}$ & $<0,0001$ \\
\hline $\operatorname{Raça}^{1}$ & $1,36 \mathrm{~b}$ & $1,91 \mathrm{a}$ & $1,60 \mathrm{ab}$ & $=0,0184$ \\
\hline Tipo de ordenha ${ }^{2}$ & 1,93 a & $1,91 \mathrm{a}$ & $1,08 \mathrm{~b}$ & $<0,0001$ \\
\hline Estrutura do local ordenha ${ }^{3}$ & $1,93 \mathrm{a}$ & $1,82 \mathrm{a}$ & $1,00 \mathrm{~b}$ & $<0,0001$ \\
\hline Pré-dipping ${ }^{4}$ & $1,29 \mathrm{~b}$ & $1,72 \mathrm{a}$ & $1,04 \mathrm{~b}$ & $<0,0001$ \\
\hline Pós-dipping ${ }^{5}$ & $1,72 \mathrm{a}$ & $1,91 \mathrm{a}$ & $1,20 \mathrm{~b}$ & $<0,0001$ \\
\hline Terapia da vaca seca ${ }^{6}$ & $2,36 \mathrm{a}$ & $2,81 \mathrm{a}$ & $1,64 \mathrm{~b}$ & $<0,0001$ \\
\hline Higiene de equipamentos $^{7}$ & $1,93 \mathrm{a}$ & $2,00 \mathrm{a}$ & $1,24 \mathrm{~b}$ & $<0,0001$ \\
\hline Concentrado conforme produção ${ }^{8}$ & $1,79 \mathrm{a}$ & $1,73 \mathrm{ab}$ & $1,40 \mathrm{~b}$ & $=0,0333$ \\
\hline Capineiras ${ }^{9}$ & $1,64 \mathrm{ab}$ & $1,28 \mathrm{~b}$ & $1,72 \mathrm{a}$ & $=0,0376$ \\
\hline Tipo de concentrado ${ }^{10}$ & $2,21 \mathrm{ab}$ & $2,72 \mathrm{a}$ & $1,71 \mathrm{~b}$ & $=0,0008$ \\
\hline CBT $\left(\log _{10}\right)$ & $5,22 \mathrm{~b}$ & $4,83 \mathrm{~b}$ & $5,83 \mathrm{a}$ & $<0,0001$ \\
\hline $\operatorname{CCS}\left(\log _{10}\right)$ & 5,77 & 5,71 & 5,74 & $=0,8204$ \\
\hline Álcool & 76,32 & 76,12 & 74,87 & $=0,3210$ \\
\hline Teor de gordura & 4,24 & 4,45 & 4,27 & $=0,2847$ \\
\hline Teor de proteína & $3,45 \mathrm{~b}$ & $3,64 \mathrm{a}$ & $3,50 \mathrm{~b}$ & $=0,0135$ \\
\hline Teor de lactose & $4,25 \mathrm{~b}$ & $4,42 \mathrm{a}$ & $4,30 \mathrm{~b}$ & $=0,0167$ \\
\hline Teor de sólidos totais & $12,89 \mathrm{~b}$ & $13,51 \mathrm{a}$ & $13,10 \mathrm{~b}$ & $=0,0114$ \\
\hline
\end{tabular}

*Médias seguidas de letras iguais não diferem entre si $(\mathrm{P}<0,05)$.

${ }^{1}$ Diversas raças 1 , somente Jersey $2 ;{ }^{2}$ balde ao pé 1 , ordenha semi ou canalizada $2 ;{ }^{3}$ estábulo convencional 1 , sala de ordenha $2 ;{ }^{4}$ não usa pré-dipping 1 , usa pré-dipping $2 ;{ }^{5}$ não usa pós-dipping 1 , usa pós-dipping $2 ;{ }^{6}$ não faz terapia intramamária da vaca seca 1 , faz às vezes 2 faz terapia da vaca seca 3 ; ${ }^{7}$ não utiliza água quente, detergente ácido e alcalino 1, utiliza água quente, detergente ácido e alcalino $2 ;{ }^{8}$ não fornece concentrado conforme a produção de leite 1 , fornece concentrado conforme a produção de leite 2 ; ${ }^{9}$ não utiliza capineiras 1 , utiliza capineiras 2 ; ${ }^{10}$ fornece concentrado energético 1 , fornece concentrado proteico 2 , fornece concentrado energético e proteico 3 .

O fator 2 (Tab. 1 e Fig.1) é representado pelos grupos 1 e 2 (Tab. 3). Pode-se afirmar que esses produtores possuem maior poder econômico para aquisição de novas tecnologias e maior facilidade ao acesso às informações técnicas para a melhoria das estratégias de alimentação, para a adoção de práticas recomendadas no manejo da ordenha, para a produção e a qualidade do leite.
O grupo 3 (Tab. 3) é composto por propriedades com menor nível tecnológico, onde se tem menor adoção das práticas recomendadas no manejo de ordenha, estrutura inadequada para a ordenha, menor critério na alimentação dos animais e rebanho composto por diversos tipos de raças, que produzem leite em menor quantidade e qualidade. Dessa forma, o grupo 3 é composto por produtores com menor poder econômico para 
a aquisição de novas tecnologias, menor acesso às informações técnicas de estratégias de alimentação, produção e qualidade do leite. Nesse caso, deve-se levar em consideração a menor capacidade de investimento, de melhoria da produção e da qualidade do leite, a menor capacitação para a produção leiteira, assim como fatores culturais, que implicam a resistência dos produtores em adquirir ou adotar novas tecnologias (Martins et al., 2007).

\section{CONCLUSÃO}

A região sul do estado de Santa Catarina caracteriza-se por pequenas propriedades e pela agricultura familiar. Os produtores adotam diferentes critérios de manejo de ordenha e de alimentação dos animais, propiciando a produção do leite com diferentes níveis de qualidade. As propriedades são diferenciadas, principalmente, pela produção de leite/vaca/dia, pela estrutura do local de ordenha, pelas práticas de higiene na ordenha e pela raça leiteira utilizada. Assim, as propriedades que apresentam infraestrutura mais adequada para a produção, maior adoção das práticas recomendadas de manejo de ordenha e critérios de alimentação mais adequados produzem leite de melhor qualidade.

\section{AGRADECIMENTOS}

Á Fundação de Amparo à Pesquisa e Inovação do Estado de Santa Catarina (Fapesc), pelos recursos financeiros; ao Governo do Estado de Santa Catarina, por meio da Fumdes, pela concessão de bolsa de pós-graduação; aos produtores e às indústrias de laticínios participantes do projeto, os quais foram peças fundamentais para realização deste estudo.

\section{REFERÊNCIAS}

BARCHIESI-FERRARI, C.G.; WILLIAMSSALINAS, P.A.; SALVO-GARRIDO, S.I. Inestabilidad de la leche asociada a componentes lácteos y estacionalidad en vacas a pastoreo. Pesqui. Agropecu. Bras., v.42, p.1785-1791, 2007.

BODENMÜLLER FILHO, A.; DAMASCENO, J.C.; PREVIDELLI, I.T.S. et al. Tipologia de sistemas de produção baseada nas características do leite. Rev. Bras. Zootec., v.39, p.1832-1839, 2010 .
BRASIL. Ministério da Agricultura, Pecuária e Abastecimento. Instrução Normativa No 62 de 29 de setembro de 2011. Regulamento técnico de produção, identidade e qualidade do leite tipo A, do leite pasteurizado e do leite cru refrigerado e de seu transporte a granel. Diário Oficial da União, Brasília, DF, 2011.

COSTA, J.H.C.; HÖTZEL M.J.; LONGO,C. et al. A survey of management practices that influence production and welfare of dairy cattle on family farms in southern Brazil. J. Dairy Sci., v.96, p.307-317, 2013.

ECKSTEIN, I.I.; POZZA, M.S.S.; ZAMBOM, M.A. et al. Qualidade do leite e sua correlação com técnicas de manejo de ordenha. Sci. Agrar. Paran., v.3, p.143-151, 2014.

ELMOSLEMANY, A.M.; KEEFE, G.P.; DOHOO, I.R. et al. The association between bulk tank milk analysis for raw milk quality and on-farm management practices. Prev. Vet. Med., v.95, p.32-40, 2010.

GABBI, A.M.; MCMANUS, C.M.; A.V. SILVA, A. et al. Typology and physicalchemical characterization of bovine milk produced with different productions strategies. Agr Syst., v.121, p. 130-134, 2013.

GARCÍA, C.G.M.; DORWARD, P.; REHMAN, T. Farm and socio-economic characteristics of smallholder milk producers and their influence on technology adoption in Central México. Trop. Anim. Health Prod., v.44, p.1199-1211, 2012.

MACHADO, S.C. Fatores que afetam a estabilidade do leite bovino. 2010. 191f. Tese (Doutorado) - Universidade Federal do Rio Grande do Sul, Porto Alegre, RS.

MARQUES, L.T.; FISCHER, V.; ZANELA, M.B. et al. Fornecimento de suplementos com diferentes níveis de energia e proteína para vacas Jersey e seus efeitos sobre a instabilidade do leite. Rev. Bras. Zootec., v.39, p.2724-2730, 2010.

MARTINS, P.R.G.; FISCHER, V.; RIBEIRO, M.E.R. et al. Produção e qualidade do leite em sistemas de produção da região leiteira de Pelotas, RS, Brasil. Ciênc. Rural, v.37, p.212217, 2007. 
MIGUEL, P.R.R.; POZZA, M.S.; CARON, L.F. et al. Incidência de contaminação no processo de obtenção do leite e suscetibilidade a agentes antimicrobianos. Semina. v.33, p.403-416, 2012.

MOREIRA N.V.; MONTANHINI, M.T.M. Contaminação do leite na ordenha por microorganismos proteolíticos e lipolíticos. Rev. Bras. Hig. Sanid. Anim., v.8, p.29-38, 2014.

PICOLLI, T.; ZANI, J.L.; BANDEIRA, F.S. et al. Manejo de ordenha como fator de risco na ocorrência de microorganismos em leite cru. Semina. v.35, p.2471-2480, 2014.

RANGEL, A.H.N.; ARAÚJO, V.M.; BEZERRA, K.C. et al. Processo de higienização nos equipamentos de ordenha em propriedades leiteiras . Acta Vet. Brasilica, v.8, p.107-112, 2014.

SAS/STAT user's guide 8.0. Cary-NC: SAS Institute. 2002

SILVA, B.M; ANTUNES, R.B.; MIRANDA JUNIOR, G.X. et al . Plano integrado de recursos hídricos da bacia hidrográfica do rio Tubarão e complexo Lagunar: caracterização climática da região. Florianópolis, 2002. Disponível em: <http: www.aguas.sc.gov.br>. Acessado em: 01 jun. 2012

STUMPF, M.T.; FISCHER, V.; MC MANUS, C.M. et al. Severe feed restriction increases permeability of mammary gland cell "tight junctions" and reduces ethanol stability of milk. Animal. v.7, p.1137-1142, 2013.

TRONCO, V.M. Manual para inspeção da qualidade do leite. 4.ed. Santa Maria: UFSM, 2010. 195p.
VALLING, V.M.; BELOTI, V.; BATTAGLINI, A.P.P. et al. Melhoria da qualidade do leite a partir da implantação de boas práticas de higiene na ordenha em 19 municípios da região central do Paraná. Semina. v.30, p181-188, 2009.

WILLERS, C.D.; FERRAZ, S.P.; CARVALHO, L.S. et al. Determination of indirect water consumption and suggestions for cleaner production initiatives for the milk-producing sector in a Brazilian middle-sized dairy farming. J. Clean Prod., v.72, p.146-152, 2014.

WINCK, C.A.; THALER NETO, A.Perfil de propriedades leiteiras de Santa Catarina em relação à Instrução normativa. Rev. Bras. Saúde Prod. Anim., v.13, p.296-305, 2012.

WINKLER, N.C. A competição entre propriedades rurais da cadeia produtiva do leite no oeste catarinense. 2010. 90f. Dissertação (Mestrado) - Universidade Federal do Rio Grande do Sul - Porto Alegre, RS.

YALÇIN, C.; YILDIZ, A.S.; SARIÖZKAN, S. et al. Producer profiles, production characteristics and mastitis control applications at dairy herds in Konya, Burdur and Kirklareli provinces, Turkey. Ankara Üniv. Vet. Fak. Derg., v.57, p.43-48, 2010.

YUEN, S.K.; YEE, C.F.; YIN, F.H. Microbiological Quality and the impact of hygienic practices on the raw milk obtained from the small-scale dairy farmers in Sabah, Malaysia. Int. J. Agr. Food Sci., v.2, p.55-59, 2012.

ZANELA, M.B.; FISCHER, V.; RIBEIRO, M.E.R. et al. Qualidade do leite em sistemas de produção na região Sul do Rio Grande do. Pesqui. Agropecu. Bras., v.41, p.153-159, 2006. 